\title{
Efficiency of referral for suspected glaucoma
}

\author{
Maurice W Tuck, Ronald P Crick
}

Abstract

Objective-To examine the efficiency of referral for suspected glaucoma to general practitioners and consultants by optometrists.

Design-A prospective survey covering $5 \%$ of all sight tests performed by optometrists in England and Wales over six months, with analysis of referred patients.

Setting-241 optometrists' practices in areas representative of England and Wales in socioeconomic terms.

Subjects-Of 275600 people attending for a sight test, 1505 were referred with suspected glaucoma $(0.9 \%$ of those aged over 40$)$. Outcomes were recorded for 1228 patients, $1103(90 \%)$ of whom attended for examination by a consultant ophthalmologist ( $8 \%$ on a private basis). The analysis was confined to the 704 cases in which the information on diagnosis was received directly from a consultant or general practitioner.

Main outcome measures-Diagnoses reported by consultant ophthalmologists. Waiting times before an appointment for examination by a consultant ophthalmologist.

Results-Glaucoma was confirmed in 283 of the 704 referred patients, and another 222 patients were considered to require further monitoring. In all, 112 (41\%) of 275 confirmed cases of glaucoma were in patients with intraocular pressures $\geqslant 30 \mathrm{~mm} \mathrm{Hg}$. At all levels of intraocular pressure the accuracy of referral was greater when the optometrist also recorded the presence of suspicious optic discs or loss of visual field, or both; but only $331(47 \%)$ out of the 704 referred patients had been tested with a field screener. The median waiting time for an NHS clinic appointment was nine weeks. Almost a 10th of confirmed cases of glaucoma were in people in a high risk category for glaucoma who had to wait at least 14 weeks for an appointment.

Conclusions-Closer cooperation, especially at the local level, among consultants, general practitioners, and optometrists is needed to improve testing and referral for suspected glaucoma. Optometrists should be encouraged to perform all the three main tests-ophthalmoscopy, tonometry, and perimetry-in patients before referral and to report precisely on reasons for referral to help prioritisation. The optometrist's referral letter to the general practitioner should always be passed on to the consultant. Similarly, the diagnosis should always be reported back to the optometrist.

Association, King's

College Hospital, London SE5 9RS

Maurice W Tuck, BSC

(ECON), consultant economist

Ronald P Crick, FRCS,

honorary consultant

ophthalmologist

Correspondence to: $\mathrm{Mr}$ Crick.

BMY 1991;302:998-1000 usually be recognised by the sufferer. Yet late detectio means that more irreversible loss of visual field has occurred and can make the condition more difficult to treat effectively. ${ }^{1-3}$
Most referrals to consultant ophthalmologists for glaucoma are made by general practitioners. ${ }^{4}$ Three quarters of these are initiated by optometrists (ophthalmic opticians), ${ }^{5-7}$ some by ophthalmic medical practitioners, and some by the general practitioners themselves. Those initiated by general practitioners typically result from the patient already experiencing symptoms..$^{6-10}$

Some optometrists use all of the three main tests to screen for glaucoma-that is, ophthalmoscopy, tonometry, and perimetry-but performance across this profession is uneven. Though ophthalmoscopy is mandatory, only a half of people aged over 40 (the group mainly at risk) have their intraocular pressures tested with a tonometer, and less than a 10th have visual fields tested with a field screener. ${ }^{1112}$

A prospective survey has recently been conducted on behalf of the International Glaucoma Association to identify ways in which testing and referral for glaucoma can be improved. In this paper we present results that concern the efficiency of the referral process, which directly involve both general practitioners and consultant ophthalmologists.

\section{Methods}

The survey was implemented by 241 optometrists, who were mainly clustered in areas which together were representative of England and Wales in socioeconomic terms. Most were recruited by personal interview, but about a 10th responded to an appeal in optometric publications. The optometrists covered a wide cross section of the profession with respect to the differing modes of testing for glaucoma. They completed a questionnaire on each patient whom they referred with suspected glaucoma over a prospective six month period, mainly commencing between November 1988 and February 1989. The respondents performed 275600 sight tests - about five per cent of the national total-during the survey. A detailed account of methodology has been published elsewhere..$^{13}$

\section{REFERRALS}

The optometrists referred 1505 people for suspected glaucoma during the six months. This was $0.6 \%$ of the people of all ages in whom they carried out sight testsa figure within the range found in previous studies. ${ }^{514-16}$ For people aged over 40 the referral rate was an estimated $0.9 \%$. The outcome of the referral was determined for 1228 patients. Of these, 125 did not proceed for examination by a consultant ophthalmologist. Of the 1103 who were examined by a consultant, $88(8 \%)$ were examined on a private basis, with proportions varying from around $15 \%$ in the more prosperous parts of the south east to $3 \%$ in industrial areas.

Feedback information on diagnosis was provided to the optometrists on a routine basis by consultants or general practitioners in $386(35 \%)$ of the 1103 relevant cases, and in response to special inquiries in another 
$318(29 \%)$. The analysis below is confined to these 704 cases reported by the medical profession. In the remaining cases, for which the outcome was obtained from the patients, the patterns shown were similar. ${ }^{13}$

\section{Results}

\section{ACCURACY OF REFERRALS}

Table I gives the diagnoses recorded for the 704 referred patients. Glaucoma was confirmed in 283 of them, and 222 were considered to require further monitoring. The data suggest that in almost all the confirmed cases the disease was chronic.

\section{REASONS FOR REFERRALS RELATED TO ACCURACY}

Optometrists were asked to indicate which of several main reasons for referral applied in each case. Table II summarises the results. Of those 171 patients referred with (by the optometrist's measurement) intraocular pressure $\geqslant 30 \mathrm{~mm} \mathrm{Hg}$ in at least one eye, $112(65 \%)$ were definitely diagnosed as having glaucoma and only 20 were discharged as not having the disease; these 112 patients (including a few with subacute glaucoma) accounted for $41 \%$ of all cases of confirmed glaucoma. The accuracy of referral was much less in patients with lower intraocular pressures. Among the 87 people referred with intraocular pressure of $20-25 \mathrm{~mm} \mathrm{Hg}$ without other supporting reasons, only seven were definitely found to have glaucoma and 50 could be discharged.

At all levels of intraocular pressure accuracy was greater where the optometrist also recorded glaucomatous signs in the optic discs or visual fields, or both. Accuracy was low where the optometrist's action was based on either abnormal optic discs or visual fields alone and not intraocular pressure. However, where abnormal optic discs and abnormal visual fields

TABLE I - Diagnosis in patients referred for suspected glaucoma by optometrists in International Glaucoma Association survey and clinic based studies

\begin{tabular}{lcccc}
\hline & & \multicolumn{3}{c}{ Clinic based studies } \\
\cline { 3 - 5 } Diagnosis & $\begin{array}{c}\text { Survey (England and } \\
\text { Wales, 1989) }\end{array}$ & $\begin{array}{c}\text { Leeds, } \\
1981\end{array}$ & $\begin{array}{c}\text { Leicester, } \\
1987\end{array}$ & $\begin{array}{c}\text { Burton on Trent, } \\
1987\end{array}$ \\
\hline Glaucoma & 283 & 11 & 41 & 29 \\
Uncertain, follow up required & 222 & 4 & 20 & 67 \\
Not glaucoma & 199 & 19 & 32 & 24 \\
\hline Total & 704 & 34 & 93 & 120 \\
\hline
\end{tabular}

TABLE II-Number of patients referred (number diagnosed as having glaucoma, number diagnosed as having glaucoma plus number with uncertain diagnoses requiring follow up) according to reasons for referral

\begin{tabular}{|c|c|c|c|c|c|}
\hline & $\begin{array}{l}\text { High intraocular } \\
\text { pressure only }\end{array}$ & $\begin{array}{l}\text { Suspicious optic } \\
\text { discs }\end{array}$ & Visual field loss & $\begin{array}{l}\text { Both suspicious } \\
\text { optic discs and } \\
\text { field loss }\end{array}$ & Total \\
\hline \multirow{7}{*}{$\begin{array}{c}\text { Intraocula } \\
\geqslant 30 \\
26-29 \\
20-25 \dagger\end{array}$} & & \multicolumn{4}{|c|}{ High intraocular pressure also a reason } \\
\hline & $\mathrm{mm} \mathrm{Hg})^{\star}:$ & & & & \\
\hline & $76(38,59)$ & $65(48,62)$ & $13(11,13)$ & $17(15,17)$ & $171(112,151)$ \\
\hline & $84(25,60)$ & $54(29,45)$ & $24(11,21)$ & $16(11,15)$ & $178(76,141)$ \\
\hline & $87(7,37)$ & $87(24,59)$ & $35(9,23)$ & $43(19,31)$ & $252(59,150)$ \\
\hline & & \multicolumn{4}{|c|}{ High intraocular pressure not a reason } \\
\hline & & $28(6,13)$ & $9(2,4)$ & $52(20,34)$ & $89(28,51)$ \\
\hline otal & $247(70,156)$ & $234(107,179)$ & $81(33,61)$ & $128(65,97)$ & $690(275,493)$ \\
\hline
\end{tabular}

¿Based on eye with higher pressure.

Includes some patients with intraocular pressure $<20 \mathrm{~mm} \mathrm{Hg}$ but with a difference of $\geqslant 3 \mathrm{~mm} \mathrm{Hg}$ between eves.

TABLE III - Effects of testing with field screener in people referred for suspected glaucoma with intraocular pressure 20-25 mm Hg according to reasons for referral. Figures are numbers of patients diagnosed as having glaucoma out of total numbers referred.

\begin{tabular}{lccccc}
\hline & $\begin{array}{c}\text { High intraocular } \\
\text { pressure only }\end{array}$ & $\begin{array}{c}\text { High intraocular } \\
\text { pressure and } \\
\text { suspicious optic discs }\end{array}$ & $\begin{array}{c}\text { High intraocular } \\
\text { pressure and } \\
\text { field loss }\end{array}$ & $\begin{array}{c}\text { High intraocular } \\
\text { pressure suspicious } \\
\text { optic discs and } \\
\text { field loss }\end{array}$ & Total \\
\hline $\begin{array}{l}\text { Patients not tested } \\
\text { Patients tested }\end{array}$ & $5 / 64$ & $22 / 65$ & Not applicable & Not applicable & $27 / 129$ \\
& $2 / 23$ & $2 / 22$ & $9 / 31$ & $17 / 40$ & $30 / 116$ \\
\hline
\end{tabular}

occurred together the proportion of referrals in which the diagnosis was confirmed approached the average for total referrals. This overall category, where intraocular pressure was not a reason for referral, accounted for $28(10 \%)$ confirmed cases.

Only $331(47 \%)$ of all the 704 referred patients had been tested by the optometrist with a field screener. Thus many of those for whom loss of visual field was not given as a reason for referral had not, in fact, been tested in this respect. We analysed data for referred patients who were or were not tested with a field screener separately. The average accuracy of referral was similar in both groups, largely because if intraocular pressure was very high optometrists commonly referred people without conducting the third test. Nevertheless, the analysis emphasises that field screening generally enables a case to be more precisely described and the risk of glaucoma thereby better assessed at the primary level. Table III illustrates this for the people with intraocular pressure $20-25 \mathrm{~mm} \mathrm{Hg}$, the referral criteria for whom are particularly important in determining the load on hospital clinics.

\section{WAITING TIMES}

Table IV gives an analysis of waiting times between referral by the optometrist and examination by a consultant ophthalmologist in an NHS clinic. For patients $(n=525)$ for whom the relevant data were recorded by respondents the median wait was nine weeks and the arithmetic mean 12 weeks. This compares with a median of four weeks (mean five weeks) for those who were examined privately. Taking 14 areas in which at least 15 referrals were recorded, the median waiting time varied from five weeks to 15 weeks. Within virtually all these areas a wide range of waiting times applied - from one day up to six months or more.

Table V shows that waiting times were considerably shorter for patients who were referred with a relatively high intraocular pressure. Where suspicious optic discs or loss of visual field, or both, were additional reasons for referral this did not generally increase the priority of an appointment.

About a quarter of patients in whom glaucoma was subsequently confirmed had to wait 14 weeks or more for their initial appointment. Of these, a third had intraocular pressure $\geqslant 30 \mathrm{~mm} \mathrm{Hg}$ or intraocular pressure $26-29 \mathrm{~mm} \mathrm{Hg}$ combined with suspicious discs or visual fields, or both. These people were at identifiably high risk of glaucoma.

Optometrists referred patients directly to a hospital clinic in 4\% of cases; in a quarter of these "acute symptoms" was recorded as a reason for referral.

\section{REFERRED PATIENTS WHO DID NOT ATTEND FOR EXAMI-} NATION

In about a third of the 125 cases in people who did not attend for examination the general practitioner decided against referral, although some of the people were in the high risk categories. The other two thirds did not even approach their general practitioner or, if they did, subsequently failed to attend a clinic. Probable reasons for this recorded by the respondent optometrist in 39 cases were: "unhelpful mentality" (16); "disabled or ill" (6); "moved away" (6); "referred for other diseases" (2); "letter lost" (1); "died" (8). Non-attenders could be up to $15 \%$ of all patients referred when the 277 patients referred in whom the outcome was not documented are taken into account.

\section{Discussion}

This prospective survey, which was very large compared with previous studies, indicates that each year in England and Wales optometrists refer about 
TABLE IV-Distribution of waiting times for examination by consultant ophthalmologist in NHS clinic in patients referred for suspected glaucoma

\begin{tabular}{lc}
\hline No of weeks & No $(\%)$ of patients \\
\hline$<5$ & $79(15)$ \\
$5-8$ & $134(26)$ \\
$9-12$ & $113(22)$ \\
$13-16$ & $71(14)$ \\
$17-20$ & $58(11)$ \\
$21-24$ & $17(3)$ \\
$25-28$ & $21(4)$ \\
$>28$ & $32(6)$ \\
\hline
\end{tabular}

50000 patients for suspected glaucoma who subsequently attend for examination at an NHS eye clinic or privately. ${ }^{13}$ On the survey's evidence, two out of three referrals are justifiable in that the patient either is found to have glaucoma by the consultant ophthalmologist or is called back for further examination. This is consistent with the data of previous clinic based surveys (table I) ${ }^{5-7}$ and also with data from two Scottish studies. ${ }^{11 \times}$ Only $13 \%$ of optometrists' referrals were based on an intraocular pressure $<26 \mathrm{~mm} \mathrm{Hg}$ in the absence of other supporting evidence (table II). The proportion of unnecessary referral is not excessive, although improvements might reasonably be sought.

TABLE $\mathrm{V}-$ Median waiting times in days for examination by consultant in NHS clinic (number of patients referred) according to reasons for referral of patients for suspected glaucoma

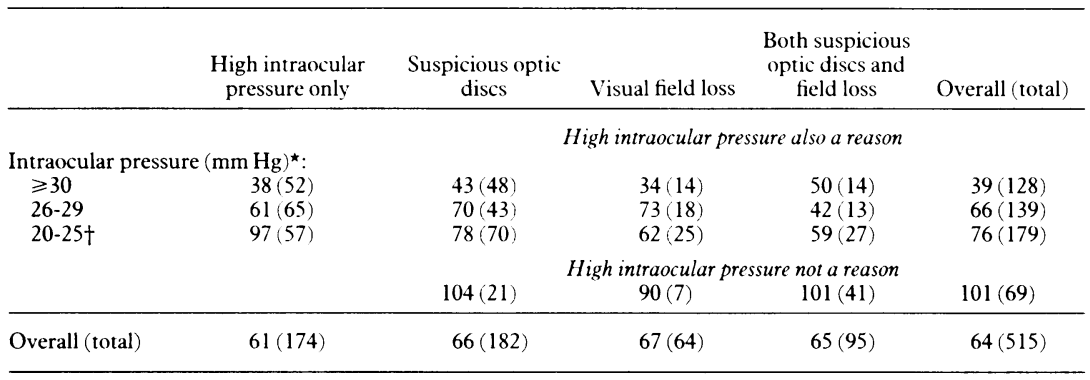

$\star$ Based on eye with higher pressure.

tIncludes some patients with intraocular pressure $<20 \mathrm{~mm} \mathrm{Hg}$ but with a difference of $\geqslant 3 \mathrm{~mm} \mathrm{Hg}$ between eyes.

One of our main findings was that two fifths of all patients in whom glaucoma was confirmed had (by the optometrists' measurements) intraocular pressure $\geqslant 30 \mathrm{~mm} \mathrm{Hg}$. Patients with very high intraocular pressure, especially those in whom suspicious optic discs or loss of visual field, or both, are additional reasons for referral, are particularly liable to suffer severe loss of sight as a result of the disease ${ }^{1-3}$; consequently, these people need to be identified and treated as early as possible.

Previous analysis of other data from the survey suggests that optometrists can usually judge correctly at the time of referral those cases in which glaucoma is "almost definite." But although consultants often give them some priority, almost a 10th of confirmed cases of glaucoma were in people in high risk categories who had to wait at least three to four months before an initial clinic appointment.

With limited clinic resources prioritisation is an aspect of the referral process which now deserves close attention. The relations shown in tables II and III between different reasons for referral and risk of glaucoma are directly relevant to this problem and could help all those professionally involved to agree practical criteria for referral and to distinguish more accurately the relative urgency of individual referrals. Better communication between the medical profession and optometrists is, in any event, necessary to improve the efficiency of referral. Optometrists should be urged to be precise in reporting all of their reasons for referral and encouraged clearly to identify those patients in whom glaucoma is almost definite. It is always helpful for the optometrist's report to be included with the general practitioner's referral letter. Similarly, optometrists might reasonably expect to be informed of the ophthalmologist's diagnosis, which the survey shows happens in only a third of all referrals. With routine feedback constructive advice can be directed towards the minority of optometrists who refer too readily.

The question of direct referral by optometrists for suspected glaucoma has been raised before. ${ }^{61718}$ The survey shows that this already occurs occasionally, especially in cases of subacute glaucoma; it might be extended further, but only in defined circumstances where in urgent cases it would enable patients to be examined without delay, the approval by telephone of the general practitioner being obtained if possible.

Closer cooperation at the local level would also encourage optometrists to use all the three main tests for glaucoma. The main benefit is likely to be in improved detection rates; the survey's data on this have yet to be fully analysed. The importance of routine tonometry in all patients aged over 40 is, however, clearly reflected in the present results. They also indicate how both ophthalmoscopy and perimetry can contribute to an effective screening system and emphasise that appreciable error is attached to findings based on any single test alone. It is particularly important that optometrists should test referred patients with a field screener, enabling the patient's risk of glaucoma to be better defined, which is the basis for prioritisation.

The survey confirms that there is a large scale of screening for glaucoma already continuously being undertaken by optometrists in Britain, so the best way ahead is likely to be in seeking further improvement in the present system. ${ }^{11}$ More efficient testing and referral for this serious disease would prevent much unnecessary loss of sight.

We thank all the optometrists, general practitioners, and consultant ophthalmologists who took part in this exercise; Mr R Coakes, Mrs J Curtis, Mr F Giltrow-Tyler, Mr M B R Mathalone, and Mr K Stannard for helping to provide data; Tana Trust for providing a computer; Dr B Gale of Imperial College, London, for advising on statistical matters; and Mrs Betsy Wright, Association Secretary, and Mr Donald King, administrator, of the International Glaucoma Association for their help.

1 Wilson R, Walker AM, Dueker DK, Crick RP. Risk factors for rate of progression of glaucomatous visual field loss: a computer-based analysis. Arch Ophthalmol 1982;100:737-41.

2 Vogel R, Crick RP, Newson RB, Shipley M, Blackmore H, Bulpitt CJ Association between intraocular pressure and loss of visual field in chronic simple glaucoma. Br f Ophthalmol 1990;74:3-6.

3 Grant WM, Burke JF. Why do some people go blind from glaucoma? Ophthalmologv 1982;89:991-8.

4 Mackean M, Elkington AR. Referral routes to hospital with chronic open angle glaucoma. $R M \mathcal{F}$ 1982;285:1093-5.

Clearkin L, Harcourt B. Referral pattern of true and suspected glaucoma to an adult ophthalmic out-patient clinic. Transactions of the Ophthalmology Society adult ophthalmic out-patient clinic. Trans

6. Buttain GPH, Austin DJ, Kelly SP. A prospective study to determine sources and diagnostic accuracy of glaucoma referrals. Health Trends 1988;20:43-4.

7 Harrison RJ, Wild JM, Hobley AJ. Referral patterns to an ophthalmic out patient clinic by general practitioners and ophthalmic opticians and the role of these professionals in screening for ocular disease. BMF 1988;297:1162-7.

8 Gillie RF. The source and manner of referral of chronic simple glaucom patients to hospital. Ophthalmic Optician 1982;22:586.

Steinmann WC. The 'who' and 'how' of detecting glaucoma. BMF 1982;285 1091-3.

10 Crick RP, Creaby E, Freeman S. Who detects glaucoma in the UK? Dispensing Optician 1982:34:192-4

11 Tuck M. Crick R. Testing and referral for chronic glaucoma. Health Trends $1989: 21: 131-4$

12 Tuck $M$, Testing for glaucoma-the first IGA survey revisited. Opticion $1990 ; 199 ; 5252: 16-7,24$.

13 Tuck MW. Referrals for suspected glaucoma-an IGA survey. Ophthalmic Physiol (Opt 1991;11:22-6.

14 Port MJA, Pope CA. Referrals and notifications by British optometrists. Ophthalmic Physiol Opt 1988;8:323-6.

15 Port MJA. Referrals and notifications by British optometrists within the UK 1988 survey. Ophthalmic Physiol Opt 1989;9:31-5.

16 Port MJA. BCO survey of medical referrals and notifications-1989, a preliminar report. . London: British College of Optometrists, 1989

17 Howie JGR, Taylor JL. Raised intraccular pressure-time for a rethink on referral procedure. BMF 1982;285:1009-10.

18 Kljakovic M, Howic JGR, Phillips Cl, Bartholomew RS, Brown JGS. Raised intraocular pressure: an alternative method of referral. BMf 1985;290:1043-

Accepted 14 Februan 1991 